\title{
Acceptance of Electric Vehicles Populations Distribution Network Access Capability Assessment
}

\author{
Jinyong Hu, Liang Cai, Lu Xia, Bin Li, Chang Liu \\ China Electric Power Research Institute, Beijing 100192, China
}

\begin{abstract}
With the contradiction between economic development and energy supply, environmental pollution is becoming more and more acute, saving energy and reducing consumption, reduce dependence on fossil fuels, has become an urgent need to solve the problem of sustainable development of China's economy. Electric vehicle is a new type of power system load, its charge are random in time and space, the largescale electric vehicle centralized charging will greatly affect the traditional load curve, the impact of the security and stability of the power system operation. In this context, this paper proposes a macroscopic evaluation model of bearing capacity of electric vehicles in residential area based on distribution network. The model using the probability distribution method, considering the load of the existing distribution network, analysis of the existing distribution network transformers how electric vehicles can carry charge, as well as the residential area of the original load growth, residents of the area distribution transformer changes of EV charging load bearing capacity.
\end{abstract}

KEYWORD: Assessment Model; Electric cars; Load curve

\section{INTRODUCTION}

Excessive emissions of greenhouse gases, leading to increased global warming trend. As a new generation of electric vehicles of transport, in energy conservation, reduce human dependence on fossil fuels with traditional aspects of the traditional automotive unparalleled advantage. At present, because plug-in hybrid electric vehicle, PHEV and battery electric vehicle, BEV have the ability to access grid power supplies and get a lot of attention and development.

Governments around the world have introduced policies to promote the development of the electric car industry. In USA, department of energy to lead the implementation of the EV project program, free for users of electric vehicles through the construction of home charging pile to promote the use of electric vehicles. In China, ministry of science and technology lead the implementation of the "Ten City 1000 " plan. The project plan for two or three years in some cities in China to promote new energy vehicles in buses, cars and taxis, social service vehicles in demonstration.

With the future of the popularity of electric vehicles, electric vehicle charging mass connected to the grid, power system operation and planning will produce effects can not be ignored. Electric vehicle charging will cause the load growth, if a large number of electric vehicle charging focused on peak load, peak load power will further exacerbate poor, increasing the burden on the power system.

\section{ASSESSMENT OVERVIEW}

Electric vehicle access will cause electricity load growth in the distribution network and increase the load factor of each distribution transformer. Because of the existing distribution network of the distribution transformer layout design did not consider EV charging load access, and a large number of electric vehicle access will increase the distribution transformer overload risk and influence power supply reliability of distribution network. For the evaluation of electric vehicle charging effects brought by full load of distribution network, urgent application macro probability distribution means, by studying the distribution network it's load level and load type, the unified evaluation of existing distribution network distribution transformer on load bearing capacity of the electric vehicle charging.

Charging facilities for electric vehicles including public charging stations special charging stations, distributed charging pile (machine). Public or special charging station access grid considering the 
acceptance ability of power grid, some use the line and special transformer, will not cause the distribution network transformer overload problem. Compared with the new charging stations, residential quarters electric vehicle charging infrastructure through residential areas distribution transformers connected to the grid, but the residents of the area distribution transformer capacity at the beginning of the construction selected only consider the traditional residential electricity load, electric vehicle charging load and membership with the original residential area electricity load peaks superimposed, increased distribution transformer overload risk. The study object of this article is a residential area of distribution transformer low voltage distribution network in city. After the electric vehicle access, residential load by traditional residential electricity load and electric vehicle charging load. For residential area distribution network, after a reasonable calculation of the residential area of traditional electricity load, distribution transformer is overloaded depending on the number of intra-cell electric vehicles. When the residents of the area distribution transformer to achieve overload threshold, how to find the residential area can carry the maximum number of electric vehicles. To solve the above problems, this paper proposes a macroscopic evaluation model of bearing capacity of electric vehicles in residential area based on distribution network. The model using the probability distribution method, considering the load of the existing distribution network, analysis of the existing distribution network transformers how electric vehicles can carry charge, as well as the residential area of the original load growth, residents of the area distribution transformer changes of EV charging load bearing capacity.

\section{ASSESSMENT RESULTS AND ANALYSI}

Consider 100 separate residential area. Due to differences in the number of households in the residential area, according to a city residential area statistics, resident households are divided into six orders of magnitude. In each order of magnitude, assuming a single residential households subject to evenly distribution, and randomly generated. Meanwhile, a different order of magnitude of the residential area household electricity rates by households while the number of residents varies.

According to different economic levels within the residential area residents, residential area is different, the residential area is divided into three categories: ordinary residential, medium residential, higher cell. Three types of residential electricity load calculation, the proportion of each type of residential areas by the following table lists all of the residents in the district.
Table 1 residential area classification data

\begin{tabular}{|l|l|l|l|}
\hline $\begin{array}{l}\text { Residents cell } \\
\text { type }\end{array}$ & $\begin{array}{l}\text { Ordinary } \\
\text { residential }\end{array}$ & $\begin{array}{l}\text { Medium } \\
\text { residential }\end{array}$ & $\begin{array}{l}\text { Higher } \\
\text { residential }\end{array}$ \\
\hline Calculated load & $4 \mathrm{KW} /$ house & $6 \mathrm{KW} /$ house & $10 \mathrm{KW} /$ house \\
\hline Residential area & $<80 \mathrm{~m}^{2}$ & $80 \sim 120 \mathrm{~m}^{2}$ & $>120 \mathrm{~m}^{2}$ \\
\hline The proportion & $60 \%$ & $30 \%$ & $10 \%$ \\
\hline
\end{tabular}

In order to get the community distribution transformer capacity, assuming that all cells use the S9 type $10 \mathrm{kV}$ distribution transformers. Figure 3 shows the probability distribution of the residential area of distribution transformer actual load rate. As can be seen from the figure, a large residential area distribution transformer actual load rate between 0.455 to 0.530 concentrated. The distribution of residential areas in line with the requirements of grid operation, and operating principles of distribution transformers economy.

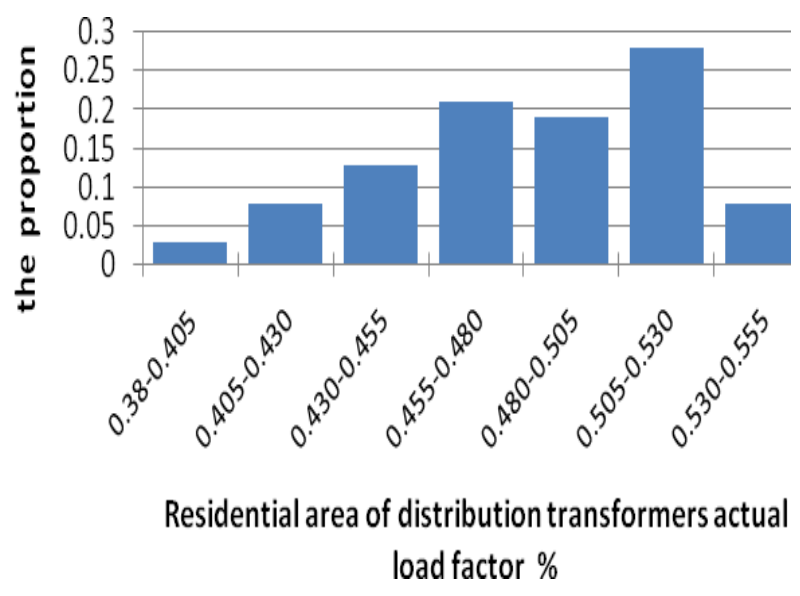

Figure1 Residential area distribution transformer load rate the probability distribution

According to the electric vehicle charging starts time, the probability distribution function of driving mileage, randomly generated 1000 car electric cars analog electric vehicle charging process, assuming each electric car is equipped with a charging device of charging power $3.5 \mathrm{KW}$, get electric vehicle charging load distribution.

\subsection{Other electricity load carrying capacity assessment when it remains unchanged}

The results in this case are shown below. As can be seen, under the electricity load of existing residents, when the electric vehicle reaches $15 \%$ penetration rate, part of the ordinary residential area of distribution transformer overload situation began to appear. When penetration reaches $25 \%$ and $35 \%$, medium residential areas and residential areas began to appear higher distribution transformer overload conditions. When penetration reaches $100 \%$ of the time, $100 \%$ of ordinary residential area, $65 \%$ of 
medium and 50 percent of the residential area of higher residential area appear distribution transformer overload situation. Overall, the average household to maintain an electric car, there are $85 \%$ of the distribution transformer can not meet the power needs.

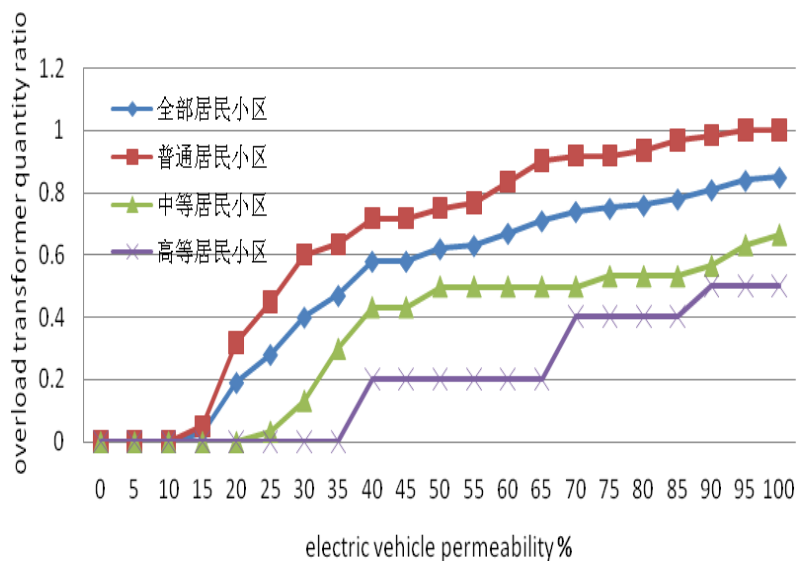

Figure2 The number of residential area of distribution transformer overload ratio and electric vehicle permeability

\subsection{Consider the load bearing capacity growth}

The results in this case are shown below. Theannual residential electricity load year-on-year growth rate of $2.1 \%$. Electric vehicle penetration rate increase of $1 \%$ per year, to 2017, three types of residents in the area are distribution transformer overload, electric cars at the permeability is about $3 \%$. In this rate, 10 years later, about $60 \%$ of the distribution transformer overload; 30 years later, all of the residential area of distribution transformers are unable to meet the distribution needs of the district, at this point the permeability of the electric vehicle is $30 \%$ to $40 \%$.

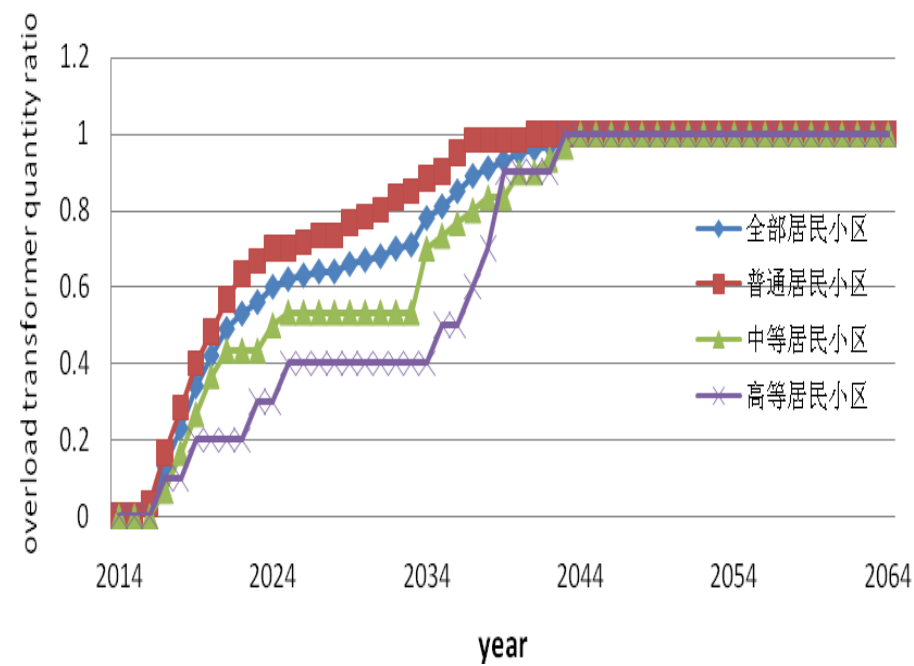

Figure 3 Consider 50 years residential area of distribution transformer overload quantity of load growth than the development of relations

\section{CONCLUSIONS}

Electric car for its good environmental effects and flexible forms of energy use, the international community has become universally recognized as one of the important development direction of the automotive industry. In this context, this paper proposes a macroscopic evaluation model of bearing capacity of electric vehicles in residential area based on distribution network. For residential area distribution network, after a reasonable calculation of the residential area of traditional electricity load, when the residents of the area distribution transformer to achieve overload threshold, how to find the maximum number of electric vehicles that can carry a residential area, according to the different permeability of electric vehicle, analog part of ordinary residential area of distribution transformer overload conditions. By accepting groups access capability of electric vehicles on the grid evaluation, can be a good guide to make recommendations for network planning, reduce grid load, reduce the impact on power quality and so on.

\section{REFERENCES}

[1] Shengxin SU. Fulfill grid social responsibilities to promote energy conservation and emission reduction. Power DSM, 2012, 14 (3) : 1-4.

[2] Wenliang $\mathrm{Wu}$, Discussion on Development Trend of Battery Electric Vehicles in China and Its Energy Supply Mode. Power System Technology, 2009, 33 (3) :1-5.

[3] Tzuu-Hseng S. Li, Shih-Jie Chang, Yi-Xiang Chen,etc. Implementation of human-like driving skills by autonomous fuzzy behavior control on an FPGA-based car-like mobile robot using Infrared Sensors. IEEE Transactions on Industrial Electronics, 2003:145-164.

[4] Sortomme E, EI-Sharkawi M A. Optimal Charging Strategies for Unidirectional Vehicle-to-Grid. Smart Grid, IEEE Transactions on, 2011, 2(1): 131-138.

[5] MOTTO K,LI Y,HUANG A Q. Comparison of the Stateof-the-art High Power IGBTs,GCTs and ETOs. New Orleans (LA, USA), 2000. 1129-1136.

[6] WU Zhao-lin, CHEN Ping-ping, TAN Ling-yun. Short Circuit Current Limiter in AC Network. Journal of Zhejiang University (Science), 2001, (01): 41-45. doi: 10.1631/jzus.2001.0041.

[7] Samuel V. Araújo, Benjamin Sahan, Peter Zacharias. Comparative Evaluation of SiC-JFETs applied to Power Converters in Renewable Energy Systems. Proceedings of the 9th International PCIM China Conference, 2010:215221.

[8] Chris Mi,Tim Lin. Design and Testing of Silicon Carbide JFETs Based Inverter. 2009 IEEE 6 (th) International Power Electronics and Motion Control Conference-ECCE Asia Conference Digests,2009:2287-2291.

[9] Xu Guohua, Yu Kun, Shen Xiong. A Depth-setting TUV control system based on RS-485 network//2nd International Conference on Manufacturing Science and Engineering. Clausthal-Zellerfeld: Trans Tech Publication, 2011:2295-2299. 